\title{
Emergence of a new GII.17 norovirus variant in patients with acute gastroenteritis in Jiangsu, China, September 2014 to March 2015
}

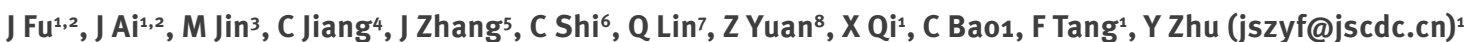

1. Key Lab of Enteric Pathogenic Microbiology, Ministry of Health, Jiangsu Provincial Center for Disease Control and Prevention, Nanjing, China

2. These authors contributed equally to this work

3. Institute for Viral Diseases Control and Prevention, Chinese Center for Disease Control and Prevention, Beijing, China

4. Nanjing Maternity and Child Health Care Hospital, Nanjing, China

5. Suzhou Center for Disease Control and Prevention, Suzhou, China

6. Wuxi Center for Disease Control and Prevention, Wuxi, China

7. Changzhou Center for Disease Control and Prevention, Changzhou, China

8. Zhenjiang Center for Disease Control and Prevention, Zhenjiang, China

Fu J, Ai J, Jin M, Jiang C, Zhang J, Shi C, Lin Q, Yuan Z, Qi X, Bao C, Tang F, Zhu Y. Emergence of a new GII.17 norovirus variant in patients with acute gastroenteritis in Jiangsu, China, September 2014 to March 2015. Euro Surveill. 2015;20(24):pii=21157. Available online: http://www.eurosurveillance.org/ViewArticle. aspx?Articleld $=21157$

Article submitted on 27 May 2015 / published on 18 June 2015

From September 2014 to March 2015, 23 outbreaks of norovirus (NoV) acute gastroenteritis occurred in Jiangsu, China. Partial sequencing of the NoV capsid gene suggested that 16 of the 23 outbreaks were related to a new GII.17 variant. This variant was first detected in sporadic specimens in October 2014, and became predominant in February 2015. Analysis of the RNA-dependent RNA polymerase (RdRp), and complete capsid including the protruding domain $\mathrm{P}_{2}$ sequences confirmed this GII.17 variant as distinct from previously identified GII variants.

Norovirus (NoV) is a major cause of viral gastroenteritis and is the main aetiological agent ofoutbreaks of acute gastroenteritis [1]. It is estimated that each year NoV cause 64,000 episodes of diarrhoea requiring hospitalisation and 900,000 clinic visits among children in industrialised countries, and up to 200,000 deaths of children $<5$ years of age in developing countries [2].

NoVs are classified into six genogroups, GI-GVI, of which genogroup I, II, and IV are responsible for disease in humans [3,4]. Genogroups are subdivided further into genotypes. To date, based on RNA-dependent RNA polymerase (RdRp) and capid gene sequences, 31 and 22 genotypes of GII NoVs have been respectively determined [5]. Of these, GII.4 caused at least six epidemics of gastroenteritis worldwide over the past 20 years (1995-1996, 2002, 2004, 2006, 2009, and 2012) with the emergence and rapid global spread of viral variants [6]. In contrast, GII.17 NoV has rarely been reported as a major genotype causing diarrhoea.
In late 2014, the Emergent Public Health Event Information Management System (EPHEIM) in Jiangsu province observed an increase of NoV outbreaks compared with previous seasons. Data from these outbreaks indicated that this increase was associated with the emergence of a new variant of GII.17, which was rarely reported in China before 2014. Surveillance of NoV in both outbreak and sporadic cases was conducted from September 2014 to March 2015 to study the molecular epidemiology characteristics of GII.17associated diarrhoea in Jiangsu province, China.

\section{Methods}

Surveillance of gastroenteritis

Outbreaks of gastroenteritis and the occurrence of sporadic cases were monitored through different surveillance systems.

Outbreak data were obtained from EPHEIM. An acute gastroenteritis outbreak was defined as $\geq 20$ cases of vomiting and/or diarrhoea associated with a common exposure.

Data on sporadic cases of gastroenteritis in the September 2014 to March 2015 period originated from two surveillance systems in Jiangsu province. The first was the comprehensive surveillance of infectious diarrhoea, which was launched in March 2012 for epidemiological and aetiological surveillance of diarrhoea in children ( $\leq 15$ years-old) and adult outpatients. This surveillance was conducted via 26 hospitals located in Nantong, Wuxi and Xuzhou, three cities chosen for their location in the southern, central and northern 


\section{FIGURE 1}

Numbers of laboratory-confirmed norovirus (NoV) outbreaks per month in Jiangsu province, China, September 2014-March 2015 (n=23)
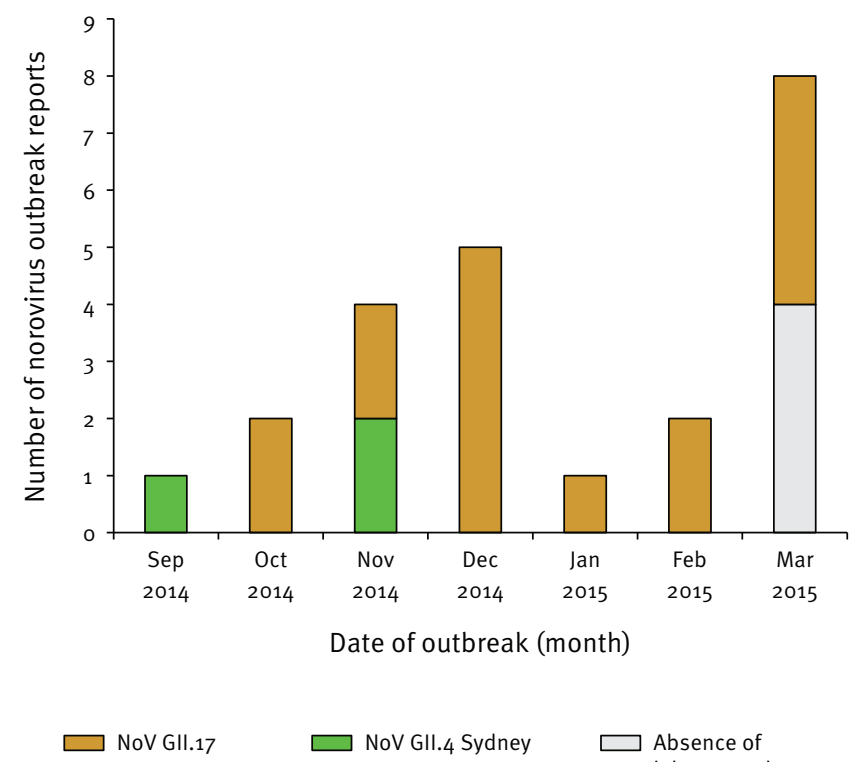

part of the province. Nantong, Wuxi and Xuzhou have a population of 7.298 million, 6.484 million and 8.591 million respectively, and totally account for $28 \%$ of the province's whole population (79.395 million). The second surveillance system for sporadic cases was that of diarrhoea of viral origin in Jiangsu province, which was launched in January 2006 for the epidemiological and aetiological surveillance of viral diarrhoea in children hospitalised in Suzhou Children's Hospital in Suzhou. This hospital is the second largest paediatric hospital in Jiangsu province.

Sporadic specimens that were laboratory-confirmed for any viral agent causing gastroenteritis were submitted to the laboratory of Jiangsu Provincial Center for Disease Control and Prevention (JSCDC) on a monthly basis for further analysis.

\section{Testing samples for norovirus}

For viral RNA extraction, a $10 \%$ (wt/vol) stool suspension in RNase-free water at a total volume of $1 \mathrm{ml}$ was centrifuged for $5 \mathrm{~min}$ at 2,370xg. The supernatant was further processed with a MagMAX-96 Viral RNA Isolation Kit (Applied Biosystems, CA, US) on an automated MagMAX Express24 Magnetic Particle Processor (Applied Biosystems, CA, US) according to the manufacturer's instructions.

The presence of NoV RNA was tested for GIl NoVs by using the Qiagen Probe RT-PCR Kit (Qiagen, Hilden, Germany) on a 7500 real-time PCR platform (Applied Biosystems, Singapore) with primers $(\operatorname{Cog} 2 F / \operatorname{Cog} 2 R)$ as described previously [7].
Molecular characterisation of the norovirus RNA from NoV positive specimens was analysed by reverse transcription-polymerase chain reaction (RT-PCR) directed at the region $C$ of the capsid gene (open reading frame (ORF)2; 344bp), using the previously described primers G2SKF/G2SKR [8].

Region A sequences of the RdRp gene in ORF1 were obtained by using a semi-nested GII-specific primer set (NV2F/G2SKR for a first-round PCR and p289lUB/ G2SKR for a second-round PCR) [8-10], which amplified a region of $1,095 \mathrm{bp}$ in the ORF1/ORF2 junction of the viral genome.

Extracted viral RNA was reverse transcribed to CDNA with a VN3T20 primer by using the Superscript III cDNA synthesis kit (Invitrogen, CA, US). ORF2 gene sequences encoding the major capsid protein viral protein 1 ( $\left.\mathrm{VP}_{1}\right)$ were obtained by using a semi-nested PCR GII-specific primer set (COG-2F/VN3T2O in the first-round $P C R$ and $\mathrm{G}_{2} \mathrm{SKF} / \mathrm{VN}_{3} \mathrm{~T}_{20}$ for the second-round PCR) $[7,8,11]$.

The PCR products were purified and then sent to the Sangon Biotech (Shanghai) Company for sequencing. The nucleotide sequences data of GII.17 variants were deposited in GenBank under accession numbers KR270442-KR270449.

Preliminary genotypes were assigned by using the norovirus genotyping tool (http://www.rivm.nl/mpf/ norovirus/typingtool).

The phylogenetic analysis of aligned sequences was carried out using Molecular Evolutionary Genetics Analysis (MEGA) 5.1 [12]. The reliability of the phylogenetic tree was assessed by bootstrap sampling of 1,000 replicates, and genetic distances were calculated by Kimura's 2 parameter method [13].

\section{Results}

\section{Epidemiological features and genotyping of noroviruses}

From September 2014 to the end of March 2015, there were 23 norovirus laboratory-confirmed outbreaks reported to EPHEIM in Jiangsu province, substantially higher than during the same time period in the previous years 2013 to 2014 . JSCDC received specimens from all outbreaks up to February 2015, however not from all the outbreaks in March 2015. This resulted in specimens being available from 19 of the 23 outbreaks. Sequence analysis of the Region $C$ of the capsid gene from these 19 outbreaks (Figure 1) showed that three outbreaks (3/23) were caused by GIl.4 Sydney, while the other 16 outbreaks (16/23) were all caused by a novel Gll.17 variant. This novel variant was first identified in October 2014 and became the dominant strain from December 2014 to March 2015 (Figure 1).

During the study period, 132/1,077 sporadic specimens were positive for norovirus (79/783 outpatient, 
Monthly distribution of norovirus (NoV) genotypes among sporadic NoV infections and monthly detection rate of NoV among specimens from sporadic cases of gastroenteritis, Jiangsu province, China, September 2014-March 2015

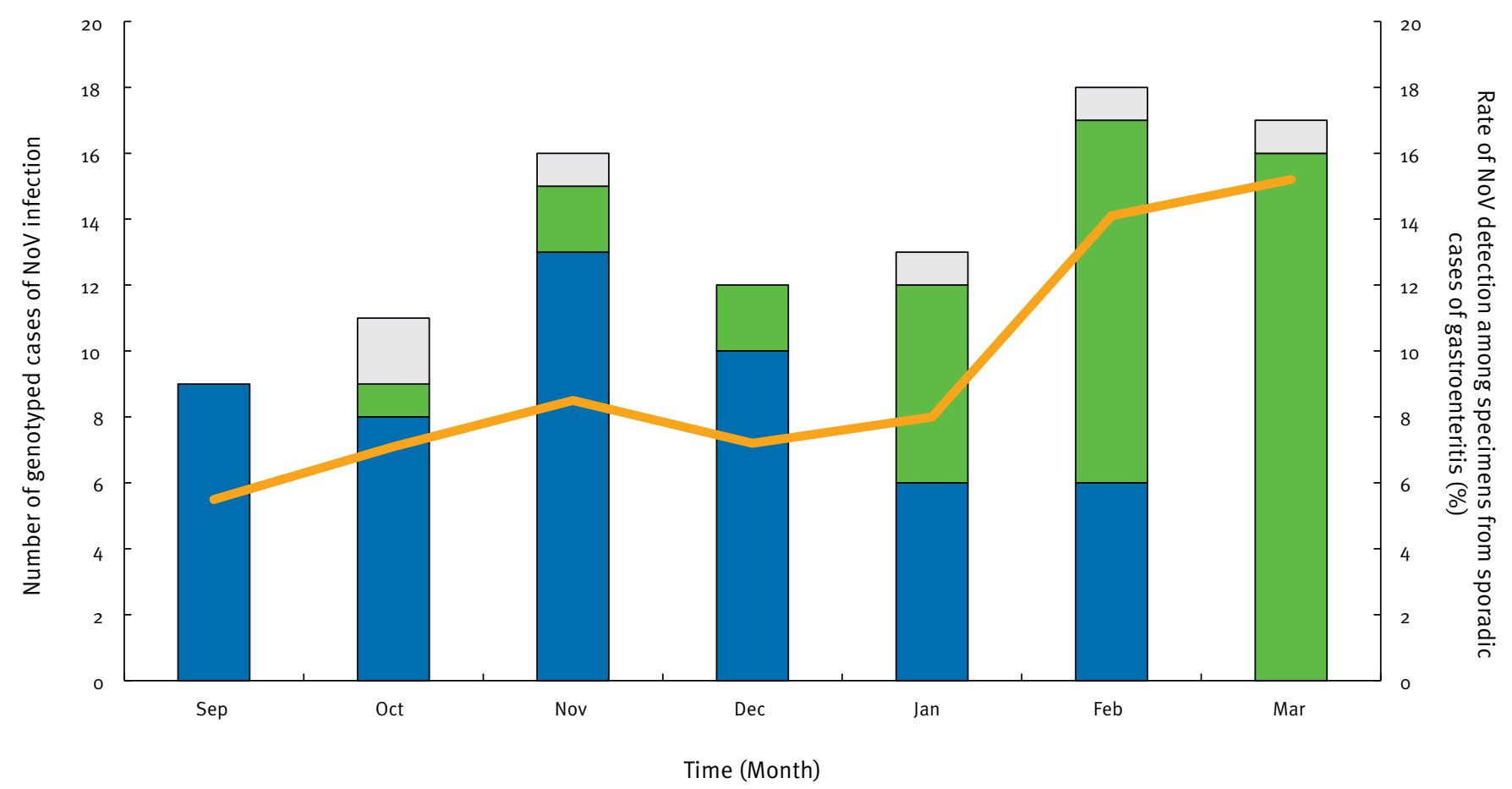

$\square$ NoV GII.4 Sydney $\square$ NoV GII.17 $\square$ NoV GII.Other Rate of NoV detection

During the study period, $132 / 1,077$ specimens obtained from sporadic cases of gastroenteritis were positive for NoV. The orange curve shows a plot of monthly detection rates of NoV among specimens.

Of the 132 specimens testing positive for norovirus, genotype was determined for a total of 95 samples. The chart vertical bars represent the total monthly number of specimens of each genotype.

and 53/294 hospitalised children), and partial capsid sequences (Region C) of 95 strains were sequenced, including 57/79 outpatient, and 38/53 hospitalised children. The sequencing of the 95 sporadic specimens resulted in the identification of five capsid genotypes (GII.2, GII.3, GII.13, GIl.4 Sydney, and GII.17). A novel Gll.17 variant was first identified in October 2014 with only one strain, compared with eight strains of GIl.4 Sydney. Gll.4 Sydney variant remained the dominant strain from September to December 2014 (9/9 in September, 8/11 in October, $13 / 16$ in November, and $10 / 12$ in December). In January 2015 , the proportion of GII.4 Sydney decreased to $6 / 13$, but that of the GII.17 variant increased to 6/13. In February 2015, the proportion of Gll.17 variant further increased to $11 / 17$ making it the predominant variant. This predominance continued in March 2015 when Gll.4 Sydney was no longer detected. Along with the increased number of confirmed NoV Gll.17 specimens, a higher detection rate of NoV among samples from sporadic cases of gastroenteritis was observed in February and March of 2015 (Figure 2).

\section{Phylogenetic Analysis}

The Region A and complete VP1 region of eight GII.17 variants (3 specimens from 3 respective outbreaks and 5 sporadic specimens) were further compared with other Gll.17 strains by phylogenetic analysis.

The Gll.17 strains were segregated into three distinct genetic groups both in Region A (Figure 3a) and VP1 region (Figure $3 b$ ).

In the tree based on Region A, the GIl.17 strain characterised in 1978 grouped with a Gll.4 Rpdp, forming Cluster I. This cluster appeared to be ancestral to GII.17 sequences reported after 2003. The Gll.17 variants identified in the period from 2004 to 2011 formed Cluster II and the variants originating from 2013 to 2015 formed Cluster III. Sequences from Cluster II and Cluster III shared a high nucleotide identity with GII.3 reference strains, especially those in Cluster III (Figure 3a).

In the tree based on the VP1 gene, the Gll.17 variants from 1978 to 2002 formed Cluster I, those from 2005 


\section{FIGURE 3}

Phylogenetic trees based on (a) Region A including the RNA-dependent RNA polymerase in open reading frame (ORF) 1 and (b) the complete major capsid protein viral protein 1 (VP1) in ORF 2
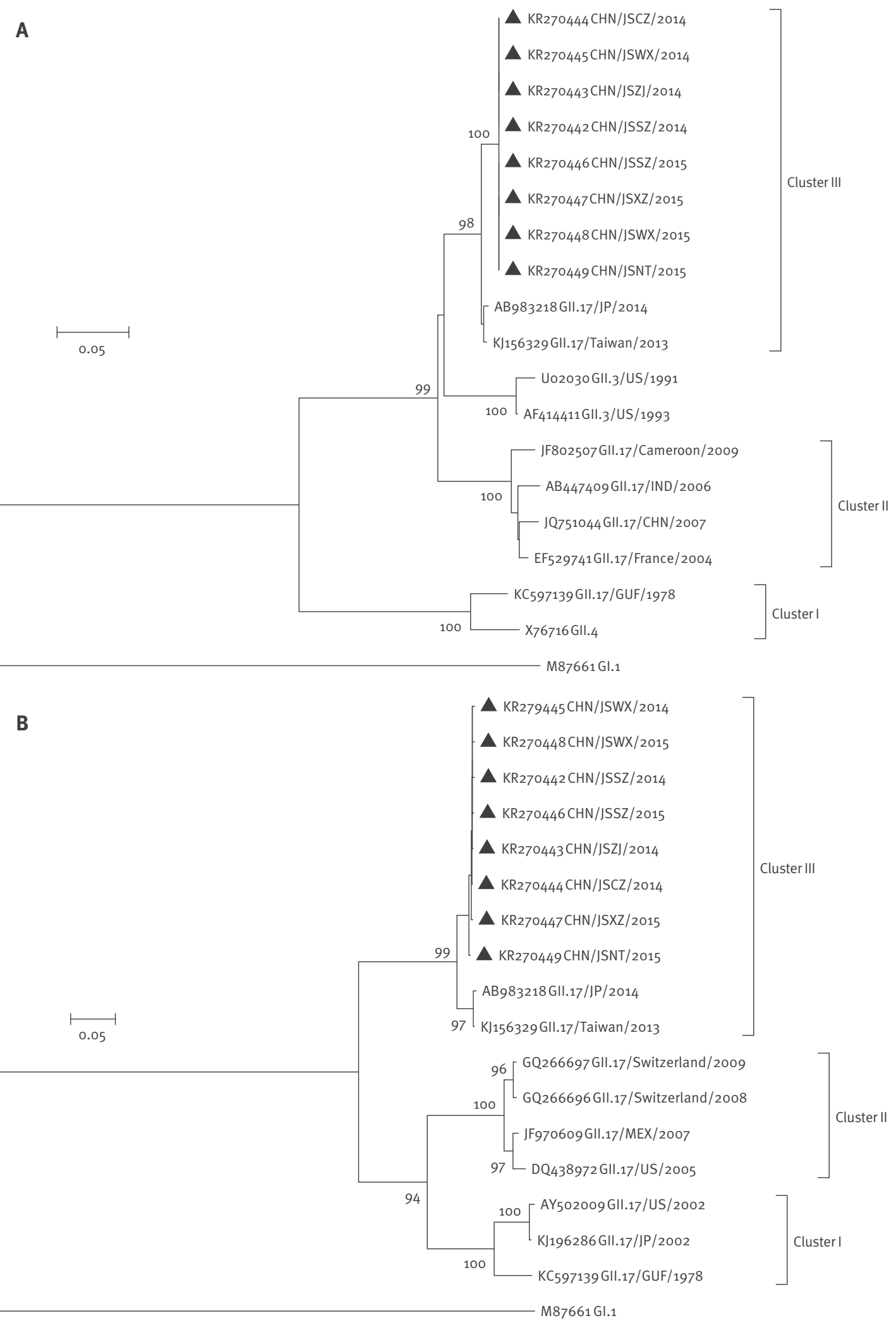

The scale bars indicate the number of nucleotide substitutions per site for the phylogenetic trees.

The numbers on the branches represent the percentage bootstrap support for the nodes after 1,00o iterations. Genbank accession numbers of all sequences used for the phylogenetic analysis figure in the respective trees.

In the two trees, the GII.17 respective VP1 and Region A sequences obtained from the eight strains characterised in the present study (Jiangsu province, China, October 2014-March 2015) are indicated by black triangles. 


\section{RGD/K Epitope A Site I Epitope A Site II}

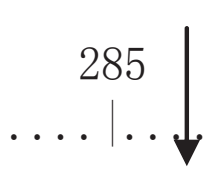

KC597139 GUF/1978 SGICAFRGKL

AY502009 US/2002

KJ196286 JP/2002

DQ438972 US/2005

JF970609 MEX/2007

GQ266696 SUI/2008 TGICAFRGKI

GQ266697 SUI/2009 TGICAFRGKI

KJ156329 TW/2013

AB983218 JP/2014

KR270442 CHN

KR270445 CHN

KR270447 CHN
SGICAFRGRV

SGICAFRGRV

SGICAFRGRV

SGICAFRGRV

SGICAFRGRV

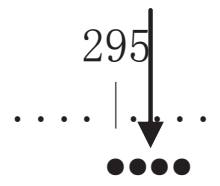

TADVHQSHDD

TADVDGSH--

TADVDGSHDD

SADVQNSHQD

SADAQNSHQD

SADVQSSHQD

SADVHSSHQD

TA--ETDHRD

TA-ETDHRD

TA-QINQRD

TA-QINQRD

TA-QINQRD

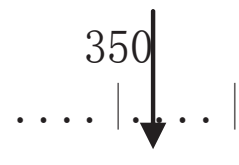

NPNTTRAHEA NPNTTRAHEA NPNTTRAHEA GNNTTRAHEV GNNTTRAHEV NXNTTRAHEV NXNTTRAHEV APGSTRAHEA APGSTRAHEA APGSTRAQQA APGSTRAQQA APGSTRAQQA

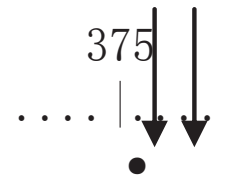

INFGSTSDDVNFGSTSTDVNFGSTSTDINFGSESEDINFGSESDDINFGSESEDINFGSESDDVNFRSNDNDVNFRSNDNDVNLRISDNDD VNLRISDNDD VNLRISDNDD
385<smiles>C[Al]1C=CI1C</smiles>

FQLQQPTKFT FQLQQPTKFT FQLQQPTKFT FQVGPPTKFT FQVGPPTKFT FQIGPPTKFT FQISPPTKFT FQXXQPTKFT FQXXQPTKFT FQXXQPTKFT FQXXQPTKFT FQXXQPTKFT

\section{Epitope D}

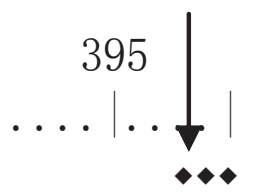

KC597139 GUF/1978 PVGIKXXESG AY502009 US/2002 KJ196286 JP/2002 DQ438972 US/2005 PVGIXXIESG PVGIXXIESG PVGIKXXETG JF970609 MEX/2007 PVGIKXXETG GQ266696 SUI/2008 PVGIKXXETG GQ266697 SUI/2009 PVGIKXXETG KJ156329 TW/2013 PVGINXXDGD AB983218 JP/2014 KR270442 CHN KR270445 CHN KR270447 CHN
PVGINXXDGD PVGVNDDDDG PVGVNDDDDG PVGVNDDDDG
Epitope E

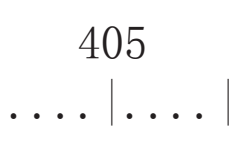

HDFDQWALPR HEFDQWALPR HEFDQWALPR HSFRQWDPPN HPFRQWDLPN HPFNQWDLPN HPCNQWDLPN HPFRQWELPD HPFRQWELPD HPFRQWELPN HPFRQWELPN HPFRQWELPN<smiles>CC(C)(C)C</smiles>

YSGHLTLNMN YSGHLTLNMN YSGHLTLNMN YSGALTLNMN YSGALTLNMN YSGALTLNMN YSGALTLNMN YSGLLTLNMN YSGLLTLNMN YSGELTLNMN YSGELTLNMN YSGELTLNMN

\section{Site III}<smiles>CC(C)(C)[AsH3]</smiles>

GEQLLFFRSN GEQLLFFRSN GEQLLFFRSN GEQLLFFRSN G-

GEQLLFFRSN GEQLLFFRSN GEQLLFFRSF GEQLLFFRSF GEQLLFFRSF GEQLLFFRSF GEQLLFFRSF

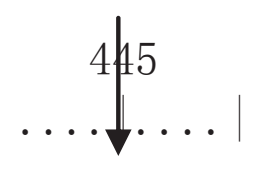

VPCAGGVSDG VPCAGGVSDG VPCAGGVSDG VPCAGGVSEG

VPCAGGVSDG VPCAGGVSDG VPCSGGYNQG VPCSGGYNQG VPCSGGYNQG VPCSGGYNQG VPCSGGYNQG

The VP1 amino acid numbering is based on the GII.17 prototype strain KC $597139 /$ GUF/1978. Dots indicate sequence identity among sequences presented in the alignment.

Amino acid positions corresponding to GII.4 predicted antibody binding regions epitope A, D, E [14] are marked by symbols: black circles, epitope A; black diamonds, epitope D; black square, epitope E.

Grey regions indicate the RGD motif [15] and site I, II, and III, which are putative histo-blood group antigen (HBGA)-binding sequences of GII NoV genotypes [16]. 
to 2009 formed Cluster II and those from 2013 to 2015 formed Cluster III.

All of the eight Gll.17 variants reported here from Jiangsu province were in Cluster III and grouped with Gll.17 strains from Taiwan (KJ156329, 2013) and Japan $(A B 983218,2014)$ in both the polymerase- and VP1 region-based trees.

Twelve GII.17 capsid protein VP1 sequences from 1978 to 2014 were aligned, including nine GII.17 sequences released previously in the GenBank database and three sequences from representative strains obtained in our study. Sequence data showed that amino acid (aa) differences occurred mostly in the protruding $\mathrm{P}_{2}$ domain (Figure 4), particularly at aa 295-297, 376, 398-400 and 414 which form the predicted antibody binding regions in variant GII.4; epitope A (aa295-297, 376), epitope D (aa398-400) and epitope E (aa 414) [14]. In addition, some of the Gll.17 strains, including the new Gll.17 strains reported here, had a K289R mutation in the alert RGD/K-like motif, located at positions 287289 [15]. In the three histo-blood group antigen (HBGA) binding sites, a single aa change $\left(\mathrm{H}_{353} \mathrm{Q}\right)$ at site I and a single aa (D380) insertion peripheral to site II occurred in the outbreak representative strains [16].

\section{Discussion}

Through the web-based surveillance system EPHEIM, increased levels of NoV activity were detected in late 2014 compared with previous season in Jiangsu province, China. Our findings suggest that this coincided with the emergence of a novel Gll.17 variant, which caused most $(16 / 23)$ of the NoV outbreaks reported between September 2014 and March 2015 in the province. Due to unavailability of laboratory data from four outbreaks in March, the number of Gll.17-associated outbreaks could have been underestimated.

The novel variant was first noted in October of 2014, and spread rapidly throughout the province, causing an increasing number of outbreaks. During the course of the winter and early spring it became the predominant cause of NoV outbreaks (Figure 1), replacing the GII.4 Sydney variant starting from December 2014. Newly identified emerging variant that become predominant have been previously reported, in particular GII.4 variants, and these can also be associated with atypical increases in the incidence of acute gastroenteritis $[17,18]$. In Jiangsu province for example, an earlier dominant variant, Gll.4-2006b, had been replaced by GII.4 Sydney in 2012/13 [19].

Based on the surveillance of NoV sporadic cases in this study, while the number of NoV GII.4 Sydney cases decreased in January 2015, sharp increases in the number of GII.17 cases were observed in February and March (Figure 2). In these two months the detection rate of NoV-positive specimens among specimens of sporadic cases of gastroenteritis also increased.
Phylogenetic analysis of GII variants, including GII.17 strains obtained in this and other studies, suggests that RNA recombination, a significant driving force in viral evolution $[20,21]$ led to some characteristics of the novel GII.17 variant reported here. In the RdRp phylogenetic tree obtained in this study, the GII.17 strains formed three Clusters. Cluster I comprised the only Gll.17 strain reported before the year 2000 as well as a GII.4 variant. Cluster II and Cluster III contained RdRp sequences of Gll.17 strains, all found after 2003, and which additionally shared a high nucleotide identity with GII.3 reference strains characterised in the 1990s, especially those in Cluster III (Figure 3a). The fact that the only one Gll.17 strain reported before 2000 had a GII.4 RdRp genotype, while most GII.17 NoVs detected in the 2000 s possessed a Gll.3-like RdRp genotype leads to hypothesise that the new GII.17 variant may be a recombinant strains with a GII.3-like RdRp gene and a GII.17 capsid gene. Interestingly, most GII.3 strains detected in the 2000 s were recombinant strains, possessing a non-GIl.3 RdRp genotype [22].

The $\mathrm{VP}_{1}$ protein $\mathrm{P}_{2}$ domain is the most exposed region of the viral particle and is well positioned to interact with potential neutralising antibodies and HBGA ligands. Mutations in this domain may have a significant effect on virus receptor binding and the host immune response to viral infection [23,24] and mutations in the $\mathrm{P} 2$ domain were observed in the new GII.17 variant. We speculate that, through the accumulation of mutations at several sites in the $P_{2}$ domain, a new antigenic variant of the Gll.17 lineage which gains the potential to escape herd host immunity could occur eventually. However, more studies, such as studies including virus-like particles (VLP)-HBGA binding assays, are needed to provide insights into the complex interaction between NoV GII.17 and their ligands.

The limitation of our study was that our results were not from nationwide surveillance but from Jiangsu province accounting for only $5.4 \%$ of the total China population. However, a similar situation to the one reported here was observed in 2012/13 with the emergence of the GIl.4 Sydney variant, which was first detected in a NoV outbreak in late 2012, and soon afterwards led to large increases in NoV activity nationwide [19].

In conclusion, the new GII.17 variant which emerged in October 2014 appears to have subsequently increasingly caused NoV outbreaks in Jiangsu province, China. This study reveals that the variant presents a number of mutations in the $P_{2}$ domain of VP1. Simultaneous dominance by GII.17 in outbreaks and sporadic infections indicates that this genotype might be established in Jiangsu Province. Nationwide surveillance for NoV outbreaks will be needed to understand epidemiological or outbreak trends related to the emergence of relatively rare GII.17 variants. Furthermore research into the mechanisms driving the evolution of NoV strains is also important for the development of effective prevention and control strategies. 


\section{Acknowledgments}

This work was supported by the Jiangsu Province Health Development Project with Science and Education (ZX201109 and RC2011085) and Jiangsu Province Science and Technology Project of Clinical Medicine (BL2014081).

\section{Conflict of interest}

None declared.

\section{Authors' contributions}

Yefei Zhu, Miao Jin, Changjun Bao, and Fenyang Tang designed the study. Jianguang $\mathrm{Fu}$, Jing $\mathrm{Ai}$, Jun Zhang, Chao Shi, Qin Lin, and Zhaohu Yuan collected, analysed, and interpreted data. Jianguang Fu and Xian Qi characterised the specimens. Jianguang Fu, Jing $\mathrm{Ai}$, and Yefei Zhu drafted the article. All authors reviewed and revised the first and final drafts of this manuscript.

\section{References}

1. Glass RI, Parashar UD, Estes MK. Norovirus gastroenteritis. N Engl J Med. 2009;361(18):1776-85. http://dx.doi.org/10.1056/ NEJMrao804575 PMID:19864676

2. Patel MM, Widdowson MA, Glass RI, Akazawa K, Vinjé J, Parashar UD. Systematic literature review of role of noroviruses in sporadic gastroenteritis. Emerg Infect Dis. 2008;14(8):1224-31. http://dx.doi.org/10.3201/eid1408.071114 PMID:18680645

3. Zheng DP, Ando T, Fankhauser RL, Beard RS, Glass RI, Monroe SS. Norovirus classification and proposed strain nomenclature. Virology. 2006;346(2):312-23. http://dx.doi.org/10.1016/j. virol.2005.11.015 PMID:16343580

4. Mesquita JR, Barclay L, Nascimento MS, Vinjé J. Novel norovirus in dogs with diarrhea. Emerg Infect Dis. 2010;16(6):980-2. http://dx.doi.org/10.3201/eid1606.091861 PMID:20507751

5. Kroneman A, Vega E, Vennema H, Vinjé J, White PA, Hansman $\mathrm{G}$, et al. Proposal for a unified norovirus nomenclature and genotyping. Arch Virol. 2013;158(10):2059-68. http://dx.doi. org/10.1007/s00705-013-1708-5 PMID:23615870

6. Karst SM, Baric RS. What Is the Reservoir of Emergent Human Norovirus Strains? J Virol. 2015;89(11):5756-9. http://dx.doi. org/10.1128/JVI.03063-14 PMID:25787285

7. Trujillo AA, McCaustland KA, Zheng DP, Hadley LA, Vaughn $G$, Adams SM, et al. Use of TaqMan real-time reverse transcription-PCR for rapid detection, quantification, and typing of norovirus. J Clin Microbiol. 2006;44(4):140512. http://dx.doi.org/10.1128/JCM.44.4.1405-1412.2006 PMID:16597869

8. Kojima S, Kageyama T, Fukushi S, Hoshino FB, Shinohara M Uchida K, et al. Genogroup-specific PCR primers for detection of Norwalk-like viruses. J Virol Methods. 2002;100(1-2):10714. http://dx.doi.org/10.1016/S0166-0934(01)00404-9 PMID:11742657

9. Nayak MK, Balasubramanian G, Sahoo GC, Bhattacharya $\mathrm{R}$, Vinje J, Kobayashi N, et al. Detection of a novel intergenogroup recombinant Norovirus from Kolkata, India. Virology. 2008;377(1):117-23. http://dx.doi.org/10.1016/j. virol.2008.04.027 PMID:18555887

10. Puustinen L, Blazevic V, Huhti L, Szakal ED, Halkosalo A, Salminen $M$, et al. Norovirus genotypes in endemic acute gastroenteritis of infants and children in Finland between 1994 and 2007. Epidemiol Infect. 2012;140(2):268-75. http://dx.doi. org/10.1017/S0950268811000549 PMID:21489338

11. Wang QH, Han MG, Cheetham S, Souza M, Funk JA, Saif LJ. Porcine noroviruses related to human noroviruses. Emerg Infect Dis. 2005;11(12):1874-81. http://dx.doi.org/10.3201/ eid1112.050485 PMID:16485473

12. Tamura K, Peterson D, Peterson N, Stecher G, Nei M, Kumar S. MEGA5: molecular evolutionary genetics analysis using maximum likelihood, evolutionary distance, and maximum parsimony methods. Mol Biol Evol. 2011;28(10):2731-9.http:// dx.doi.org/10.1093/molbev/msr121 PMID:21546353

13. Kimura $M$. A simple method for estimating evolutionary rates of base substitutions through comparative studies of nucleotide sequences. J Mol Evol. 1980;16(2):111-20. http:// dx.doi.org/10.1007/BF01731581 PMID:7463489

14. Lindesmith LC, Beltramello M, Donaldson EF, Corti D, Swanstrom J, Debbink K, et al. Immunogenetic mechanisms driving norovirus GII.4 antigenic variation. PLoS Pathog. 2012;8:e1002705. http://dx.doi.org/10.1371/journal. ppat.1002705 PMID:22615565

15. Tan M, Huang P, Meller J, Zhong W, Farkas T, Jiang X. Mutations within the $P_{2}$ domain of norovirus capsid affect binding to human histo-blood group antigens: evidence for a binding pocket. J Virol. 2003;77(23):12562-71.http://dx.doi. org/10.1128/JVI.77.23.12562-12571.2003 PMID:14610179

16. Tan $M$, Jiang X. Norovirus gastroenteritis, carbohydrate receptors, and animal models. PLoS Pathog.

2010;6(8):e1000983.http://dx.doi.org/10.1371/journal. ppat.1000983 PMID:20865168

17. Kroneman A, Vennema H, Harris J, Reuter G, von Bonsdorff $\mathrm{CH}$, Hedlund $\mathrm{KO}$, et al. Food-borne viruses in Europe network. Increase in norovirus activity reported in Europe. Euro Surveill. 2006;11:3093.

18. Siebenga J, Kroneman A, Vennema H, Duizer E, Koopmans M; Food-borne Viruses in Europe network. Food-borne viruses in Europe network report: the norovirus GII.4 2006b (for US named Minerva-like, for Japan Kobeo34-like, for UK V6) variant now dominant in early seasonal surveillance. Euro Surveill. 2008;13(2):8009. PMID:18445388

19. Fu JG, Ai J, Qi X, Zhang J, Tang FY, Zhu YF. Emergence of two novel norovirus genotype II.4 variants associated with viral gastroenteritis in China. J Med Virol. 2014;86(7):1226-34. http://dx.doi.org/10.1002/jmv.23799 PMID:24136475

20. Eden JS, Tanaka MM, Boni MF, Rawlinson WD, White PA. Recombination within the pandemic norovirus GII.4 lineage. J Virol. 2013;87(11):6270-82. http://dx.doi.org/10.1128/ JVI.03464-12 PMID:23536665

21. Bull RA, Eden JS, Rawlinson WD, White PA. Rapid evolution of pandemic noroviruses of the GII.4 lineage. PLoS Pathog. 2010;6(3):e1000831. http://dx.doi.org/10.1371/journal. ppat.1000831 PMID:20360972

22. Nayak MK, Balasubramanian G, Sahoo GC, Bhattacharya R, Vinje J, Kobayashi N, et al. Detection of a novel intergenogroup recombinant Norovirus from Kolkata, India. Virology. 2008;377(1):117-23. http://dx.doi.org/10.1016/j. virol.2008.04.027 PMID:18555887

23. Cao S, Lou Z, Tan M, Chen Y, Liu Y, Zhang Z, et al. Structural basis for the recognition of blood group trisaccharides by norovirus. J Virol. 2007;81(11):5949-57. http://dx.doi. org/10.1128/JVI.00219-07 PMID:17392366

24. Lochridge VP, Jutila KL, Graff JW, Hardy ME. Epitopes in the $P_{2}$ domain of norovirus $V \mathrm{P}_{1}$ recognized by monoclonal antibodies that block cell interactions. J Gen Virol. 2005;86(10):2799-806. http://dx.doi.org/10.1099/vir.0.81134-o PMID:16186235 